\title{
Análise da demanda do estudo em sustentabilidade e o impacto na vida de profissionais pós REABILITA
}

\author{
Analysis of the demand for sustainability studies and its impact on \\ the professionals' lives after REABILITA
}

Análisis de la demanda de estudios de sustentabilidad y el impacto en la vida de los profesionales post-REABILITA

Recebido em 10/11/2020. Aceito em 03/04/2021.

GRAFF, Paula Adjuto Martins ${ }^{1}$

GÓES, Thiago Montenegro²

1Universidade de Brasília, Faculdade de Arquitetura e Urbanismo, Laboratório de Sustentabilidade (LaSUS). Paracatu,

Minas Gerais, Brasil.

arq.paulagraff@gmail.com

ORCID: 0000-0003-4981-071X

2Universidade de Brasília, Faculdade de Arquitetura e Urbanismo, Programa de Pós-Graduação em Arquitetura e Urbanismo. Brasília, Distrito Federal, Brasil.

tgoes@hotmail.com ORCID: 0000-0002-5745-229X 


\title{
Resumo
}

A Sustentabilidade é um conceito relativamente novo e o ensino das diretrizes sustentáveis nos currículos acadêmicos de graduação ainda é uma barreira na formação dos arquitetos e urbanistas de todo o Brasil. A necessidade de conhecimentos técnicos acerca da sustentabilidade gerou demanda por cursos de pós-graduação com ênfase nesta temática. Diante desta problemática surgiu o REABILITA, que além de trabalhar este assunto tão necessário na atualidade, oferece a metodologia de Ensino a Distância que democratiza o estudo da sustentabilidade incluindo alunos de todo o Brasil e também do exterior. Assim, este trabalho objetiva entender o perfil daqueles que fizeram o curso e quais os impactos em suas vidas profissionais depois do estudo a respeito do tema. Para tanto, foi desenvolvido e aplicado um questionário aos ex-alunos do REABILITA investigando os motivos da demanda, as impressões acerca do curso, e seu impacto nas atividades e vida dos profissionais. Observou-se, a partir dos relatos, que os ex-alunos melhoraram a prática profissional. Consequentemente, têm melhorado a atuação e ensino da Arquitetura e Urbanismo Sustentáveis.

Palavras-Chave: Sustentabilidade; Arquitetura Sustentável; Ensino de sustentabilidade; Formação Profissional.

\begin{abstract}
Sustainability is a relatively new concept and the teaching of sustainable guidelines in undergraduate academic programmes is still a barrier in the training of architects and urban planners throughout Brazil. The need for technical knowledge about sustainability generates demand for postgraduate courses with an emphasis on this theme. In the face of this problem, REABILITA emerged. In addition to focus on this much needed subject nowadays, it offers the distance learning methodology that democratizes the study of sustainability by making it available for students from all over Brazil and also from abroad. Thus, this work aims to understand the profile of those who took the course and what are the impacts on their professional lives after studying the topic. With this aim in view, a questionnaire was developed and applied to the REABILITA alumni to investigate the reasons for the demand and the impressions about the course, as well as the changes in the professionals' activities and lives. It was observed, from the reports, that the alumni improved their professional practice and got better qualifications. As a result, they have improved the performance and teaching of Sustainable Architecture and Urbanism.
\end{abstract}

Key-Words: Sustainability; Sustainable Architecture; Sustainability Education; Professional Qualification.

\section{Resumen}

La sustentabilidad es un concepto relativamente nuevo y la enseñanza de directrices sostenibles en los planes de estudio académicos de licenciatura siguen siendo una barrera en la formación de arquitectos y urbanistas en todo Brasil. La necesidad de conocimientos técnicos sobre sustentabilidad genera demandas de cursos de posgrado con énfasis en esta temática. Frente a esta problemática surgió REABILITA, que además de trabajar en esta asignatura tan necesaria en la actualidad, ofrece la metodología de Educación a Distancia que democratiza el estudio de la sustentabilidad y alcanza a estudiantes de todo Brasil y también del exterior. Así, este trabajo tiene como objetivo comprender el perfil de quienes realizaron el curso y cuáles son los impactos en su vida profesional luego de estudiar el tema. Para ello, se elaboró y aplicó un cuestionario a los egresados de REABILITA para investigar los motivos de la demanda y las impresiones sobre el curso, así como los cambios en las actividades y vidas de los profesionales. Se observó, a partir de los informes, que los egresados mejoraron su práctica profesional. En consecuencia, han mejorado el desempeño y la enseñanza de Arquitectura y Urbanismo Sostenible.

Palabras clave: Sustentabilidad; Arquitectura Sostenible; Ensino de Sustentabilidad; Formación Profesional. 


\section{Introdução}

Antes de se tratar da educação da Arquitetura e Urbanismo Sustentável, é necessário conhecer a origem dos conceitos da sustentabilidade e seus desdobramentos, onde primordialmente, busca-se atender as gerações atuais sem comprometimentos dos recursos que abastecerão as gerações futuras. $O$ termo possui subjetividades às diversas áreas, porém todas as diretrizes convergem à mesma finalidade. Nos primeiros registros de projetos arquitetônicos, a preocupação era adequar as edificações ao espaço e clima. As estratégias bioclimáticas e de conforto ambiental eram utilizadas, ainda que de forma empírica, para tornar o espaço habitável adequado e com ofertas de recursos naturais do entorno. Com a evolução dos estudos, as diretrizes se tornaram cada vez facilitadoras desse caminho.

Tornou-se latente a necessidade de se aliar Sustentabilidade a Arquitetura e Urbanismo de forma mais técnica. A partir dos anos 90 , o MEC vem definindo diretrizes para a adaptação e correção de falhas nas grades curriculares de Arquitetura e urbanismo até a atualidade, como a inclusão de disciplinas voltadas aos Estudos Socais e Ambientais. Mesmo após as mudanças nos currículos, é necessário que os conceitos de Sustentabilidade sejam abordados de forma interdisciplinar, para garantir efetividade em sua empregabilidade. Enquanto estas mudanças não acontecem, se formam arquitetos e urbanistas despreparados, com grandes lacunas de conhecimento em relação à Arquitetura Sustentável.

O ensino defasado da graduação gerou a demanda por pós-graduação em sustentabilidade. Os alunos buscam se especializar, visto que as universidades, apesar dos esforços, oferecem uma abordagem defasada. Nesta lacuna, surgiu o curso Reabilitação Ambiental Sustentável Arquitetônica e Urbanística, - REABILITA, uma pós-graduação lato sensu oferecida pela Faculdade de Arquitetura e Urbanismo da Universidade de Brasília, que alia os conhecimentos da Sustentabilidade a Arquitetura e Urbanismo e conta com o método de Ensino a Distância. O EaD vem ganhando mais espaço no meio acadêmico devido à democratização do ensino, flexibilidade da rotina de estudos e avanços das Tecnologias de Informação e Comunicação, que permitem que haja uma crescente adesão entre os estudantes. Graças à esta metodologia, o REABILITA conseguiu abranger seu alcance de alunos, com presença de pessoas de todo o Brasil e do exterior, sobretudo na fase pandêmica da COVID-19.

Com o objetivo de mapear os egressos do curso, foi desenvolvido e aplicado um questionário investigativo em uma amostra de ex-alunos de edições concluídas do REABILITA, a fim de identificar os perfis dos alunos que demandam este tipo de pós-graduação, quais as suas necessidades e expectativas em relação ao curso, e por fim as mudanças causadas na atuação e carreira destes profissionais. Após este levantamento de dados, realizou-se uma análise apontando os fatores condicionantes e determinantes para estas questões levantadas.

A pesquisa procura compreender a importância do estudo da Sustentabilidade na atuação de profissionais da área de Arquitetura e Urbanismo através da investigação do curso de pós-graduação REABILITA, oferecido pela Universidade de Brasília. Para isso, foi necessário identificar os motivos pelos quais os profissionais demandam cursos com esta temática, bem como os ganhos na atuação e exercer da profissão.

\section{Referencial Teórico}

\subsection{Arquitetura Sustentável}

Para compreender o conceito de arquitetura sustentável, é importante contextualizar a noção de desenvolvimento sustentável. A Conferência da Organização das Nações Unidas sobre Meio Ambiente Humano, de 1972, teve um papel significativo e abrangência mundial por iniciar a discussão em torno do tema, ao propor um modelo de desenvolvimento econômico que respeitasse a capacidade de renovação do meio ambiente e identificasse os impactos do homem sobre o mesmo. Este conceito foi, 
então, estabelecido no Relatório de Brundtland, ONU $(1987$, p.3) como "a humanidade tem a capacidade de tornar o desenvolvimento sustentável para garantir que atenda às necessidades do presente, sem comprometer a capacidade das gerações futuras de atender suas próprias necessidades".

Sequencialmente, realizou-se a Conferência das Nações Unidas, a Rio-92, em que importantes metas foram definidas e o principal produto foi a Agenda 21. Neste evento, outros importantes tratados foram firmados, que tinham como principal viés a responsabilidade ambiental. Foi proposta uma série de políticas e ações que "enfocava, basicamente, as mudanças necessárias aos padrões de consumo, a proteção dos recursos naturais e o desenvolvimento de tecnologias capazes de reforçar a gestão ambiental dos países" (IPEA, 2009).

Diferentes são as leituras e interpretações da sustentabilidade, bem como suas tentativas e progressos na aplicação do conceito nos mais diversos setores, mas é notável que haja convergência para a mesma finalidade. A Arquitetura Sustentável, apesar de ser um termo relativamente novo, de acordo com Corbella e Yannas (2003), sempre foi uma preocupação da civilização humana, que mostrava interesse para que o espaço protegido se adapte à topografia, à vegetação e à temperatura, construindo espaços em que o ser humano encontrasse conforto. Os autores ainda apontam que:

"A Arquitetura sustentável é a continuidade mais natural da Bioclimática, considerando também a integração do edifício à totalidade do meio ambiente, de forma a torná-lo parte de um conjunto maior. É a arquitetura que quer criar prédios objetivando o aumento da qualidade de vida do ser humano no ambiente construído e no seu entorno." (Corbella e Yannas, 2003, p. 17)

Ou seja, ao longo da história da arquitetura, houve diretrizes ambientais que orientavam o desenvolvimento dos projetos, visto que o projetista considerava a relação com o meio ambiente como forma de sobrevivência, provada pela análise da arquitetura vernacular e bioclimática. O primeiro indício é de como o homem fazia naturalmente seu abrigo em harmonia e adaptação com o lugar. Em segundo, a preocupação em incorporar fatores ambientais ao desenho da edificação, fazendo uso de fontes renováveis como o sol. (ROMERO, 2001)

Portanto, projetar arquitetura e urbanismo sustentáveis é atentar para os parâmetros de conforto ambiental e eficiência energética, visto que estes devem estar de acordo com as características sociais e climáticas do local, afirma Dourados (2015), e obrigatoriamente atrelados aos contextos, anteriormente ressaltados, sociais, econômicos, geográficos, culturais e ecológicos. Sendo assim, conforme Franco (2001), todo e qualquer projeto, seja ele de um edifício ou de um bairro inteiro, deve ser desenvolvido como elemento do ecossistema urbano, visto que considerar o lote como limite da sua atuação transforma edificações voltadas apenas para o seu interior, ignorando qualquer elemento natural e demandando mais recursos artificiais para que haja o desempenho das funções ao qual foi projetado.

\subsection{Ensino de sustentabilidade na Arquitetura e Urbanismo no Brasil}

Diante de todo o contexto apresentado acerca do conceito de sustentabilidade e sua aplicação na arquitetura e urbanismo, surge o desafio de incluir o estudo do tema da formação dos profissionais, que passou por mudanças em toda a sua história. Para Barreto (2001), no Brasil, durante o período colonial, não se reconhecia o arquiteto como profissional e as escolas militares ensinavam arquitetura, ainda que precariamente. Segundo Cordeiro (2012), esse foi o panorama do ensino da Arquitetura no Brasil até o início de 1930, "quando Lúcio Costa assume a direção da então Escola Nacional de Belas Artes (ENBA) e propõe, com referências ao movimento modernista, a introdução ao pensamento urbanístico e a reforma que até hoje é referência para o ensino brasileiro de Arquitetura e Urbanismo." (CORDEIRO, 2012, p.8). 
Em 1994, o MEC, pela Portaria Ministerial n. ${ }^{\circ} 1770$ de 21 de dezembro de 1994, definiu novas diretrizes curriculares onde conteúdos, diretrizes e condições essenciais para os cursos de Arquitetura e Urbanismo almejam preservar as características da profissão, as exigências legais da regulamentação profissional e o referencial de qualidade necessário à educação e ao exercício profissional dos arquitetos e urbanistas. A partir dessa definição, passou-se a incorporar ao currículo acadêmico, ainda que de forma primária, Estudos Sociais e Ambientais, Conforto Ambiental, Tecnologia da Construção, Topografia e Planejamento Urbano e Regional, entre outras. Essas disciplinas citadas, especificamente, foram o despertar a atenção crítica para as questões ambientais e pontapé inicial para o ensino de sustentabilidade na Arquitetura e Urbanismo.

De acordo com Villela (2007), em 1999 houve novas propostas curriculares que resultaram nas Diretrizes Curriculares de 2006, que determinam que os arquitetos e urbanistas tenham a responsabilidade de desenvolver habitações duráveis e que promovam bem-estar. Para isso, a tecnologia entra como um recurso para atender questões "sociais, culturais, estéticas e econômicas das comunidades; o equilíbrio ecológico e o desenvolvimento sustentável do ambiente natural e construído; e a valorização e preservação da arquitetura, do urbanismo e da paisagem como patrimônio e responsabilidade coletiva." (VILLELA, 2007, p.86).

De acordo com Dourado (2015), na maioria das escolas de Arquitetura e Urbanismo do Brasil, verificase que os conteúdos teóricos da sustentabilidade vêm sendo ensinados sem associação com as disciplinas de projeto. Logo, considera-se um ensino diferenciado os casos em que ocorre algum método de integração.

Baseado em questionários aplicados com estudantes de arquitetura, arquitetos e, em seguida, com os premiados do Concurso Opera Prima de 2001 a 2006 Vilella (2007) identificou que:

“(...) a sustentabilidade não tem sido suficientemente abordada na graduação, e isto pode, e deve estar afetando a formação atual do arquiteto e urbanista, que termina a graduação sem uma visão global. Aqueles que se interessam particularmente pelo tema procuram cursos de pós-graduação nessa área específica sem que, todavia, a sustentabilidade arquitetônica e urbanística como um todo faça parte da bagagem teórica e técnica do arquiteto." (VILLELA, 2007, p.8).

É possível observar claramente que a demanda no tema vem crescendo cada vez mais devido à defasagem do estudo de sustentabilidade e a falta de interdisciplinaridade na graduação de Arquitetura e Urbanismo. Dessa maneira, conforme Malheiros et al. (2013, p. 541), "as instituições de educação superior já não são vistas somente como fonte única de conhecimento disciplinar e formação de profissionais que integrarão a sociedade e contribuirão para seu progresso econômico". Além disso, a educação também serve ao processo de emancipação e individual e coletiva, especialmente por oferecer exemplos de práticas sustentáveis.

Seguindo esta linha, a Faculdade de Arquitetura e Urbanismo da Universidade de Brasília, no Programa de Pesquisa e Pós-graduação, iniciou em 2006 ao curso de pós-graduação lato sensu em Reabilitação Ambiental Sustentável Arquitetônica e Urbanística - REABILITA. O curso oferece formação contínua a profissionais envolvidos e busca estudar teorias associadas à reabilitação ambiental sustentável, conhecer a legislação pertinente aos estudos do ambiente construído, estudar as práticas e as ferramentas de auxílio ao projeto arquitetônico e urbanístico, "e também analisar soluções tecnológicas sustentáveis para o diagnóstico, preservação e intervenção em edificações e conjuntos urbanos" (LaSUS, 2020, p.3). 
Seguindo esta linha, a Faculdade de Arquitetura e Urbanismo da Universidade de Brasília, no Programa de Pesquisa e Pós-graduação, iniciou em 2006 ao curso de pós-graduação lato sensu em Reabilitação Ambiental Sustentável Arquitetônica e Urbanística - REABILITA. O curso oferece formação contínua a profissionais envolvidos e busca estudar teorias associadas à reabilitação ambiental sustentável, conhecer a legislação pertinente aos estudos do ambiente construído, estudar as práticas e as ferramentas de auxílio ao projeto arquitetônico e urbanístico, e também analisar soluções tecnológicas sustentáveis para o diagnóstico, preservação e intervenção em edificações e conjuntos urbanos.

De acordo com o Laboratório de Sustentabilidade aplicada à Arquitetura e ao Urbanismo - LaSUS1 da FAU-UnB (2020), o REABILITA é responsável pela formação de mais de 500 profissionais. São alunos de todo o Brasil e também do exterior, não somente Arquitetos e Urbanistas, mas também de áreas correlatas. O LaSUS ainda salienta que o REABILITA é um curso de média duração e utiliza do método de Ensino a Distância, que propicia assim o acesso democrático, participativo e progressista às tecnologias de comunicação como uma forma paliativa, mas necessária, de oferecer melhores oportunidades àqueles que, de alguma forma, tem menor alcance à educação de qualidade.

\subsection{Educação a Distância - EaD}

Segundo o Ministério da Educação (MEC, 2016, on-line), a Educação a Distância - EaD é definido como uma "modalidade educacional na qual alunos e professores estão separados, física ou temporalmente e, por isso, faz-se necessária a utilização de meios e tecnologias de informação e comunicação". A educação a distância passou por diversas fases, vem tomando cada vez mais força e se incorporando na cultura brasileira.

De acordo com Sousa (2006, p.6), o "rápido e contínuo desenvolvimento das Tecnologias da Informação e da Comunicação (TICs) tem contribuído para que essa modalidade de educação seja um marco decisivo na ampliação das possibilidades de acesso ao conhecimento". Apesar do significativo avanço científico e tecnológico, muito ainda precisa ser feito antes de uma efetiva democratização do acesso ao conhecimento.

Há críticas a respeito da atuação do $\mathrm{EaD}$, como apontada por Lima (2007), que afirma que há uma contradição a respeito da inclusão social, porque apesar de incluir a camada mais desfavorecida da população, aumenta a oferta de cursos e continua a alimentar o neoliberalismo. Cavalcanti e Strozzi (2008) completam que, a democratização é um termo controvertido em um país como o Brasil, onde os contrastes socioeconômicos e culturais somam-se com a exclusão digital. Por outro lado, dentre as vantagens dos cursos à distância, tem-se o alcance e inclusão de um público maior e mais variado devido às:

“(...) facilidades que oferece em relação à logística de deslocamento, flexibilidade de horários, valor dos cursos, tecnologias utilizadas entre outras características inerentes. Assim, se configuram desafios para as universidades tornar os currículos mais flexíveis, como a integração de atividades pedagógicas presenciais com atividades a distância de forma inovadora." (FIUZA,2012, p.15).

\footnotetext{
1 O LaSUS foi oficialmente criado em 2005 e é coordenado pela Prof. Dra. Marta Adriana Bustos Romero, Professora Titular do Departamento de Tecnologia da FAU-UnB. É referência em pesquisa no Brasil e possui uma significativa rede de parcerias com órgãos federais (CNPq, CAPES, FINEP, FINATEC, FUNPE), outros departamentos da UnB e outras universidades nacionais e internacionais. $O$ presente artigo é contribuição para a produção acadêmica do LaSUS, por meio do REABILITA.
} 
Muitos avanços são necessários para que haja qualidade e efetividade da educação a distância, mas no atual cenário da Pandemia de COVID-19, o método, ainda como um recurso em ascensão instituições de ensino, tem se mostrado uma alternativa eficiente para que escolas e universidades não tenham grandes prejuízos na educação. No REABILITA, a metodologia aplicada desde a primeira edição vem se aprimorando e mostra aceitação dos alunos - apresentada nos resultados deste artigo - dada a qualidade da Universidade de Brasília e por ter um alcance de alunos de todo o Brasil, mas também do exterior, facilitado pelo EaD.

\section{Objetivos}

\subsection{Objetivo Geral}

O intuito deste trabalho é compreender a percepção dos ex-alunos do REABILITA - Reabilitação Ambiental Sustentável Arquitetônica e Urbanística, quanto a curso e ao conteúdo de sustentabilidade, assim como seus perfis e o impacto profissional acometido após a conclusão do curso.

\subsection{Objetivos Específicos}

Entender a necessidade de aprofundamento do estudo sobre Arquitetura e Urbanismo Sustentáveis e a demanda pela temática em cursos de pós-graduação, tendo como objeto de estudo o REABILITA.

Identificar a contribuição do curso de especialização REABILITA na capacitação de profissionais em questões de Arquitetura e Urbanismo sustentável, também os impactos causados nas carreiras, sendo eles positivos ou negativos.

Identificar se o conteúdo do REABILITA atende às expectativas dos estudantes e quais a lacunas que favorecem a evasão dos alunos e a não conclusão.

\section{Metodologia}

Para fundamentar o presente artigo, desenvolveu-se um questionário e aplicado (enviado aos e-mails cadastrados no LaSUS), exclusivamente, aos ex-alunos do curso de pós-graduação da Faculdade de Arquitetura e Urbanismo da Universidade de Brasília, o REABILITA. De acordo com Roméro (2007), a técnica de questionários permite a obtenção de um grande número de informações. Esta utilização pressupõe uma análise exaustiva das questões a serem formuladas nos sentidos de evitar termos não compreendidos pelos usuários e também à indução de respostas. Para aprimorar o questionário, realizou-se uma versão piloto com um grupo de pessoas e, a partir do retorno oferecido pelos mesmos, posteriormente ajustada à sequência de perguntas e seus enunciados.

O questionário - disponível no link de acesso: foi desenvolvido com linguagem clara e objetiva, facilitando a tomada de decisões dos respondentes com variantes simples - respostas como sim ou não e múltipla escolha - e, em questões de avaliação, buscando não induzir respostas neutras e condicionadas. Isso contribuiu também para que os respondentes não perdessem o estímulo em finalizar o questionário, se tornando rápido e fluido. A partir desta avaliação dos ex-alunos, busca-se obter resultados para desenvolver análise a partir de cruzamento de grupos de respostas. Para isso, o questionário foi dividido em seis sessões com enfoques diferentes, com questões objetivas e de respostas fechadas de múltipla escolha, majoritariamente.

A primeira sessão do questionário identificou o perfil dos profissionais que procuraram o tema sustentabilidade na pós-graduação, especificamente o REABILITA. Realizaram-se questões sobre o gênero, idade, área de formação da graduação - com sugestão de cursos afins, pois não somente arquitetos buscaram a pós-graduação, o tempo de conclusão da mesma e o tipo de instituição em que foi graduado. Também foi questionado a área de atuação profissional e seu local de exercício, variando 
de cidade pequena à metrópole, e sua a localização no Brasil ou exterior. Com isso, é possível identificar fatores limitadores ou facilitadores em diversos âmbitos, como facilidade de atuação profissional, contato com o tema sustentabilidade e aplicabilidade da mesma.

Em seguida, na segunda sessão, o questionário tratou da relação do ex-aluno com a sustentabilidade antes do REABILITA, quão familiares os conceitos eram para o mesmo, se abordagem durante da graduação foi satisfatória, e se o nível de contato foi determinante ao escolher um curso de pósgraduação com esta temática. A partir disso, é possível relacionar as informações com as regiões do Brasil que podem ter maior ou menor abordagem no tocante da sustentabilidade, e se isso é um indicativo forte para a demanda do REABILITA.

A terceira sessão passou do universo dos ex-alunos às suas experiências durante o curso REABILITA, se tornando mais específico. Nesta parte, o enfoque foi em como o ex-aluno buscou o curso, suas razões para tal e suas impressões a respeito da metodologia $\mathrm{EaD}$, da plataforma de interação entre aluno e corpo docente, se as necessidades foram supridas e por fim, se o aluno concluiu o curso. De acordo com a resposta sobre a conclusão do curso, os respondentes foram direcionados a duas sessões distintas.

Para os que não finalizaram o REABILITA, foi desenvolvida a sessão quatro, que indagou se houve dificuldades no percurso, o que motivou a não conclusão do curso - se foi algo externo ou relacionado ao mesmo - e se existe a intensão finalizá-lo. Por fim, foi solicitado que este ex-aluno registrasse suas impressões a respeito do REABILITA e alguma consideração que não foi abordada no questionário. Esta sessão é muito importante no sentido de entender a evasão do curso, se os alunos se adaptaram ao ensino à distância e se as expectativas em relação ao conteúdo foram supridas. O questionário foi encerrado nessa sessão para este grupo, visto que não há como mensurar os impactos na vida dos mesmos com o estudo não concluído.

Já aqueles que concluíram o REABILITA foram direcionados à sessão cinco. Esta foi elaborada a fim de levantar informações sobre a trajetória dos ex-alunos do início à conclusão do curso. Houve perguntas a respeito do tempo levado para finalizar do curso, nível de satisfação e percepção geral da especialização. Nesta parte, assim como nas outras, optou-se por oferecer respostas divididas em quatro escalas de avaliação. Desta forma, foi possível evitar que, com uma quinta opção sendo uma alternativa neutra, o respondente se isente de emitir opinião a respeito do tema, o que não seria desejável por não conferir consistência aos resultados.

Por fim, na sexta e última sessão, o questionário foi sobre os impactos causados, na vida daqueles que fizeram o REABILITA. Buscou-se identificar os resultados obtidos, evolução profissional e avaliar a aplicabilidade dos conceitos estudados na pós-graduação em diferentes áreas de atuação da arquitetura. Ainda nesta sessão, os ex-alunos responderam a uma questão aberta, com poucas palavras, avaliando os conhecimentos adquiridos sobre sustentabilidade no REABILITA. Todo o grupo de perguntas das duas últimas sessões foi elaborado com o intuito de obter-se avaliação do andamento do REABILITA pela ótica dos próprios usuários, além de entender o alcance dos conceitos estudados no curso, qual a possível projeção profissional ou acadêmica, e também o que pode ter mudado na vida pessoal destas pessoas.

Após todo o processo de coleta de informações, foi realizada a análise do cruzamento de dados, a fim de traçar o perfil daqueles que demandam o REABILITA, entender o porquê da procura por um curso de pós-graduação com ênfase em sustentabilidade e conhecer os impactos gerados pelo estudo desse tema na vida profissional e acadêmica dos egressos. É importante também identificar, com aqueles alunos que não concluíram o curso, quais as lacunas existentes que poderiam ser solucionadas para que a evasão seja cada vez menor. 


\section{Resultados}

Antes de iniciar a análise dos dados obtidos, é importante contextualizar que, como fator limitador da pesquisa destaca-se a dificuldade em conseguir uma quantidade maior de respondentes ao questionário que foi aplicado apenas aos ex-alunos do REABILITA, visto que somente estes seriam capazes de avaliar as mudanças que ocorreram posteriores ao curso. Como não havia vínculo entre a Universidade e a maioria dos prováveis respondentes, os contatos realizados aconteceram via e-mails cadastrados durante com a possibilidade de que muitos tenham sofrido alterações. Sobretudo, é importante ressaltar que a amostra coletada foi de 30 respostas válidas e que esta quantidade obtida, diante dos quase 600 ex-alunos (dado informado pela coordenação do curso), não invalida a pesquisa realizada. Considerando a população de profissionais já matriculados no REABILITA, com um intervalo com confiança de $90 \% \mathrm{e}$ a amostra de 30 respondentes, a margem de erro da presente pesquisa é de $14,69 \%$.

Obviamente a análise apresentada não retrata o curso como um todo, mas ainda assim é possível identificar padrões de como este grupo de profissionais enxergou a experiência da qualificação no âmbito da Arquitetura e Urbanismo Sustentável e quais foram as mudanças geradas em suas práticas profissionais. Isso responde ao objetivo proposto neste trabalho acadêmico e também aponta outras questões relevantes que são decisivas na melhoria da qualificação profissional.

\subsection{Perfil}

Traçou-se o perfil dos alunos que procuraram o REABILITA como pós-graduação, baseado em dados apontam que há predominância da identificação com o gênero feminino (mais de $65 \%$ ) dos ex-alunos. Observou-se que a maioria dos alunos tem menos de 40 anos (66\%) e até 10 anos de graduados (63\%). São presentes também na amostra, cursos como Design e Engenharia Ambiental e Sanitária, em escala reduzida em relação a grande maioria, graduada em Arquitetura e Urbanismo (96\%).

Figura 1: Gráfico dos cursos de graduação feitos pelos respondentes.

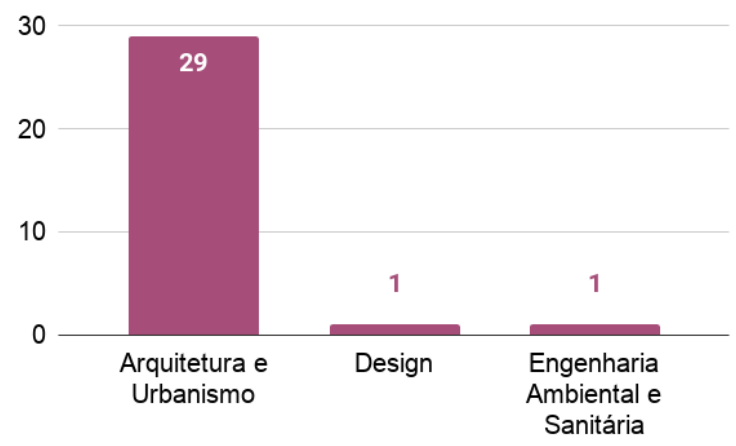

Fonte: Autores (2020)
Figura 2: Gráfico de tempo de formação dos respondentes na graduação.

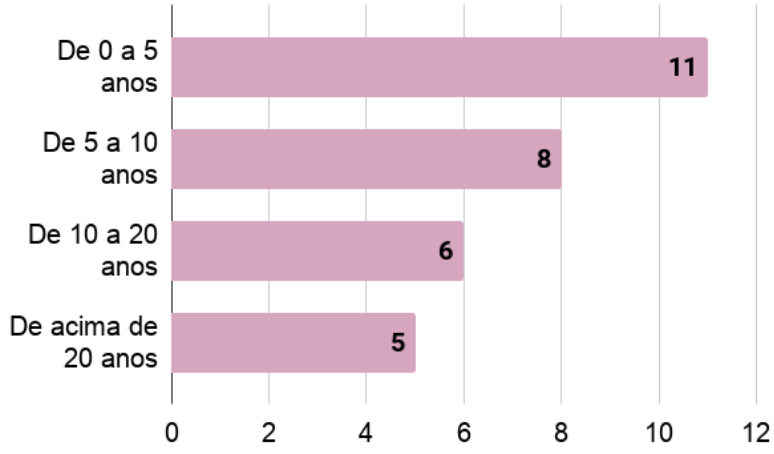

Fonte: Autores (2020)

Já em relação ao tipo de Instituição de Ensino Superior, foi questionado aos ex-alunos se haviam feito em universidades particulares ou públicas. O resultado se mostrou balanceado, sendo $53 \%$ e $47 \%$ respectivamente, como é possível conferir no gráfico a seguir.

Figura 3: Gráfico sobre o tipo de Instituição de Ensino Superior em que os respondentes se graduaram. 


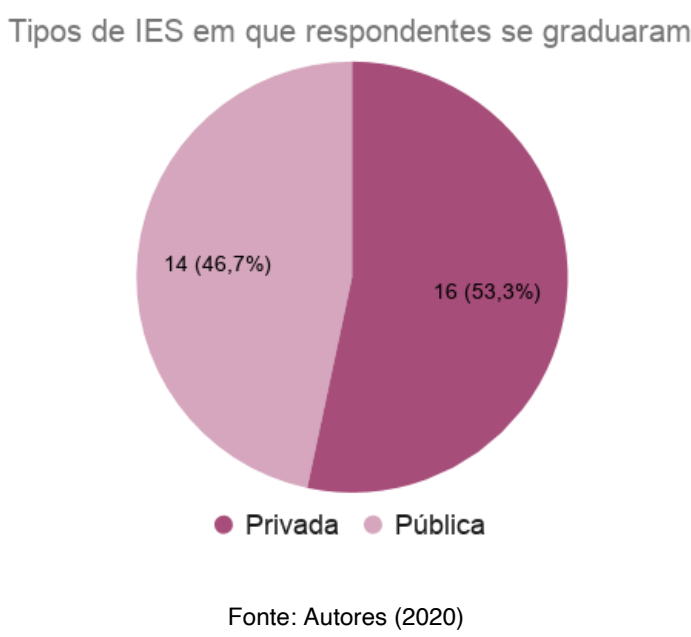

Ainda se observa que a maioria dos profissionais tem mais de uma atividade de atuação profissional, mas os grupos que atuam como autônomos, no meio acadêmico ou órgãos públicos tem maior expressividade. Essas informações refletem nas áreas de atuação, visto que quase metade dos respondentes atua na área acadêmica como professores ou pesquisadores, combinadas, em sua grande maioria, com trabalho autônomo. Além disso, pode-se constatar que $73 \%$ destes profissionais atuam no desenvolvimento de projetos, sendo a maioria combinada com alguma outra área. Execução de projetos vem em seguida, com grande diferença entre a forma de atuação anterior.

Figura 4: Gráfico de forma de atuação profissional dos respondentes.

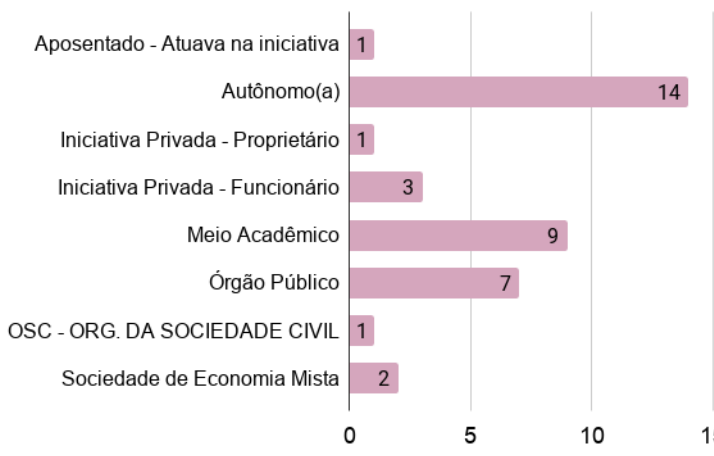

Fonte: Autores (2020)
Figura 5: Gráfico da área de atuação profissional dos respondentes.

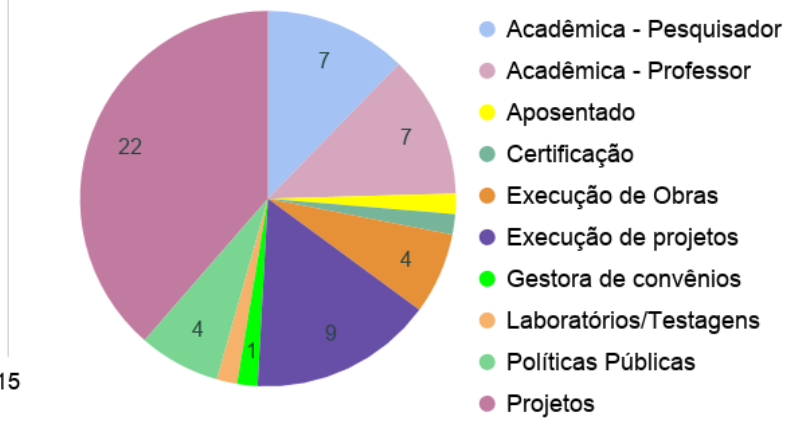

Fonte: Autores (2020)

\subsection{Contato com a sustentabilidade}

Para entender como foi o contato dos ex-alunos com a sustentabilidade antes de fazerem o REABILITA, observou-se a diferença da abordagem do tema em relação às instituições de ensino públicas e privadas, conforme figuras 6 e 7. Enquanto a maior fatia dos alunos de universidades públicas avalia como sendo positivo o contato com o tema sustentabilidade $(57,1 \%$ - Bom e $7,1 \%$ - Ótimo) nas universidades privadas, para alguns respondentes não aconteceu, e para metade dos respondentes foi de forma não satisfatória (25\% Ruim e $25 \%$ Péssima). Apesar desta análise não ser favorável às universidades privadas, a maior fatia de avaliação da abordagem como ÓTIMA veio destas IES, porém, em um balanço geral, não dá consistência a uma avaliação positiva. A partir destes dados, considera-se que são fatores determinantes para a demanda do REABILITA.

Figura 6: Gráfico: abordagem da Sustentabilidade

Figura 7: Gráfico: abordagem da Sustentabilidade na 
na graduação por alunos de IES PÚBLICAS.

Avaliação da abordagem do tema sustentabilidade na graduação por alunos de Universidades PÚBLICAS

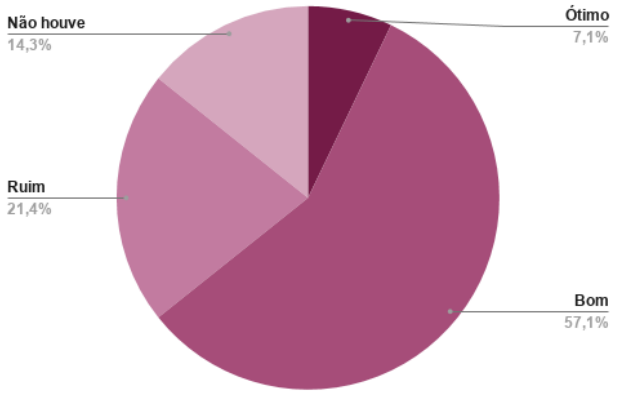

Fonte: Autores (2020) graduação por alunos de IES PRIVADAS.

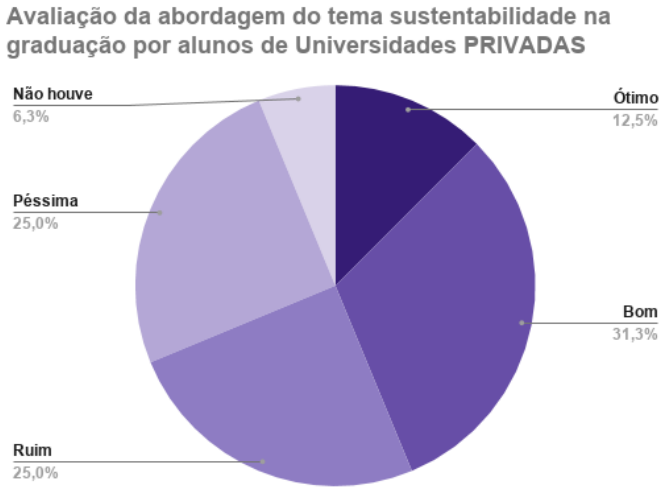

Fonte: Autores (2020)

Conforme a Tabela 1, constatou-se que a grande maioria dos respondentes teve convívio e identificava políticas públicas em relação à temática. Isso indica que o assunto não era completamente estranho para os mesmos. Porém, na relação com o tema na graduação, metade afirma ter tido contato, enquanto a outra metade não. Isso comprova a defasagem do assunto que ainda ocorre nos currículos dos cursos de Arquitetura e Urbanismo no Brasil, conforme indicado no item 2.2.

Tabela 1: Sobre o convívio do ex-aluno com a Sustentabilidade antes do REABILITA.

\begin{tabular}{lll}
\hline Tipo de contato com a sustentabilidade & Sim & Não \\
\hline Você conviveu com alguma prática sustentável antes de fazer o Reabilita? & $73,3 \%$ & $23,7 \%$ \\
$\begin{array}{l}\text { Antes do Reabilita, você se recorda de identificar alguma política pública sustentável em } \\
\text { sua cidade? }\end{array}$ & $70 \%$ & $30 \%$ \\
$\begin{array}{l}\text { Você teve contato com o tema Sustentabilidade em algum ambiente de estudo antes da } \\
\text { sua graduação? }\end{array}$ & $50 \%$ & $50 \%$ \\
\hline
\end{tabular}

Fonte: Autores (2020)

Cruzando informações relacionadas aos perfis e aprofundando mais no viés de como a sustentabilidade foi tratada na graduação, concluiu-se que o tempo de término da graduação influenciou consideravelmente na avaliação de qualidade da abordagem, que em alguns casos, não foi abordada. Conforme a Tabela 2 observou-se que quanto mais tempo o respondente tem de graduado, menor a satisfação com a abordagem da sustentabilidade; e quanto mais recente é o graduado, mais satisfeito está. Isso se dá pelo caminho que a inserção do tema vem percorrendo nos currículos acadêmicos.

Tabela 2: Avaliação da abordagem da sustentabilidade na graduação dos respondentes

\begin{tabular}{llllll}
\hline Tempo de formação na graduação & Não Houve & Péssimo & Ruim & Bom & Ótimo \\
\hline De 0 a 5 anos & - & $9 \%$ & $27 \%$ & $45 \%$ & $18 \%$ \\
De 5 a 10 anos & - & - & $38 \%$ & $63 \%$ & - \\
De 10 a 20 anos & - & $33 \%$ & $17 \%$ & $50 \%$ & - \\
De acima de 20 anos & $60 \%$ & $20 \%$ & - & - & $20 \%$ \\
Visão Geral & $\mathbf{1 0 \%}$ & $\mathbf{1 3 \%}$ & $\mathbf{2 3} \%$ & $\mathbf{4 3 \%}$ & $\mathbf{1 0 \%}$ \\
\hline
\end{tabular}

Fonte: Autores (2020)

\subsection{Demanda pelo Reabilita}

Sobre os motivos que levaram os respondentes a procurar o REABILITA, pode-se observar na figura 8 que obteve-se grande expressão nas opções: Tema de Atual Relevância, Credibilidade da Universidade de Brasília e seu corpo docente, seguido pela Conveniência do Curso EaD. De fato, os ex-alunos 
acreditam na qualidade do curso oferecido pela UnB, e o Ensino a Distância torna o curso ainda mais atrativo quando agregado a esse fator positivo. A grande parte daqueles que indicaram EaD como ponto de interesse para o REABILITA, não é da região Centro-Oeste, ou seja, o método permite que pessoas de todas as regiões do Brasil e também do exterior tenham a comodidade de ter um ensino de qualidade minimizando barreiras como localização, por exemplo, além de favorecer que pessoas estudem de acordo com sua disponibilidade de tempo e horário, dando a flexibilidade para que o estudante organize a sua própria rotina. Esta democratização é a grande vantagem do método $\mathrm{EaD}$, que permite a possibilidade de estudo em uma instituição como a UnB.

Figura 8: Gráfico das indicações de interesses pelo curso REABILITA.

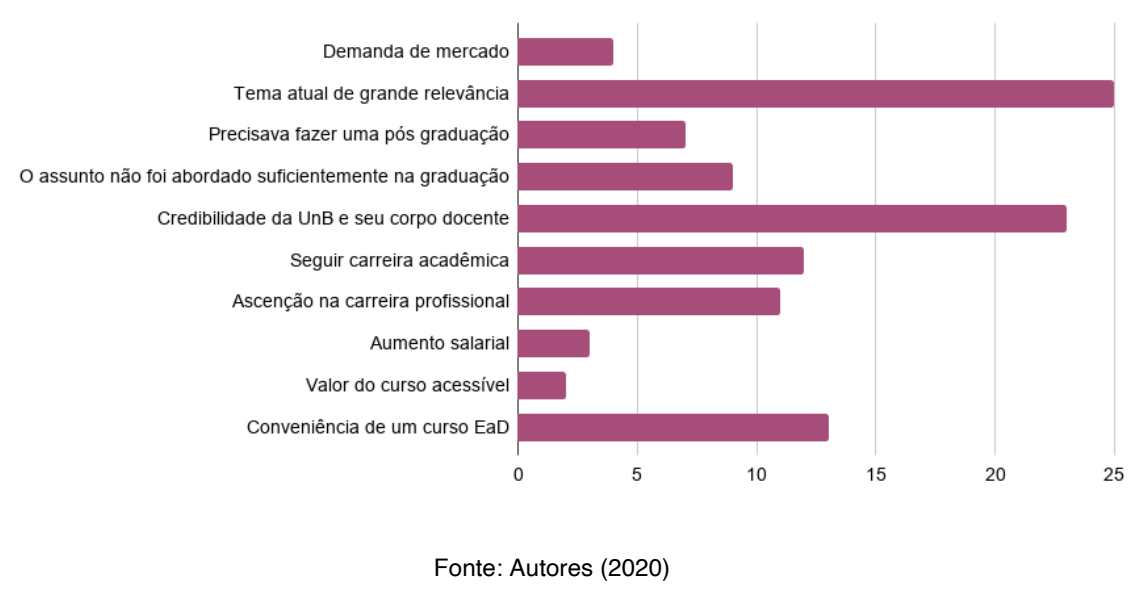

A metodologia de ensino utilizado vem sendo avaliado como positivo de um modo geral. De acordo com a Tabela 3, o índice de rejeição é considerado baixo, com o pior cenário sendo o daqueles alunos que não concluíram o curso, que neste caso, foram cinco pessoas (16\%). É importante identificar os pontos fracos, a fim de desenvolver formas de melhoria e correção, para que cada vez menos alunos se sintam insatisfeitos. Ao que tudo indica, a adaptação ao ambiente virtual e a metodologia $\mathrm{EaD}$ pode ser um dos fatores limitantes àqueles que não concluíram o curso.

Tabela 3: Indicação das experiências dos ex-alunos em relação ao REABILITA.

\begin{tabular}{lll}
\hline Questão abordada: & Não & Sim \\
\hline Houve adaptação ao método EaD & $6,7 \%$ & $93,3 \%$ \\
Conseguia resolver as dúvidas nas aulas semanais online & $10 \%$ & $90 \%$ \\
Sucesso com a plataforma de comunicação alunos x professores & $13,4 \%$ & $86,6 \%$ \\
Concluiu o curso & $16,7 \%$ & $83,3 \%$ \\
\hline
\end{tabular}

Fonte: Autores (2020) 


\section{Trajetória no Reabilita}

Desta parte em diante, o questionário foi dividido, de forma que aqueles que não concluíram o curso foram direcionados a uma sessão que busca entender os fatores que levam a evasão da pós-graduação. Como não houve andamento no curso, estas pessoas não são capazes de avaliar as questões que serão propostas no restante do questionário.

Em relação à evasão do REABILITA, $80 \%$ das pessoas indicaram que não concluíram o curso por questões pessoais, mas há indicativos como: dificuldade de manter a disciplina, questões financeiras, dificuldade de interação e comunicação com o corpo docente, não adequação ao método $\mathrm{EaD}$ e dificuldade de conciliar com outra atividade de pós-graduação. Cada uma dessas questões representa respostas de $20 \%$ da amostra que não concluiu o curso. É muito importante ressaltar que toda esta amostra indicou que deseja concluir o curso, não havendo rejeição em relação ao conteúdo abordado e/ou sua aplicabilidade.

Partindo para a avaliação da trajetória dos respondentes no REABILITA, 88\% dos ex-alunos concluiu o curso dentro dos 18 meses previstos pelo curso. Este dado reforça que a grande maioria das pessoas tem se adaptado a metodologia utilizada. Além disso, avaliações sobre o conteúdo foram realizadas, com resultados muito positivos a abordagem da Sustentabilidade pelo curso, como podem ser observados nos gráficos 10 e 11 . De acordo com os 25 respondentes que concluíram o curso, maioria acredita que o conteúdo no âmbito da Sustentabilidade é muito útil ou útil, $84 \%$ e $12 \%$ respectivamente, o que é um dado bastante positivo, visto que há tantas lacunas no ensino da temática na graduação. $O$ nível de satisfação também é bastante elevado, com valores expressivos em relação à parcela que não foi atendida com o conteúdo.

Figura 9: Gráfico sobre a utilidade do conteúdo oferecido pelo REABILITA.

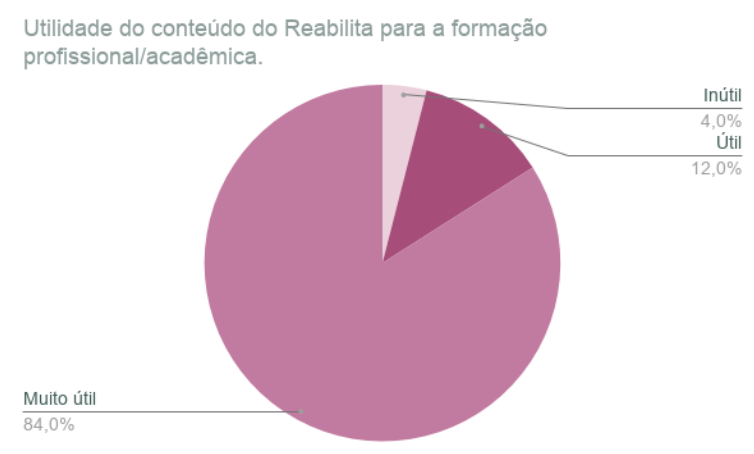

Fonte: Autores (2020)
Figura 10: Gráfico sobre a satisfação em relação ao conteúdo oferecido pelo REABILITA.

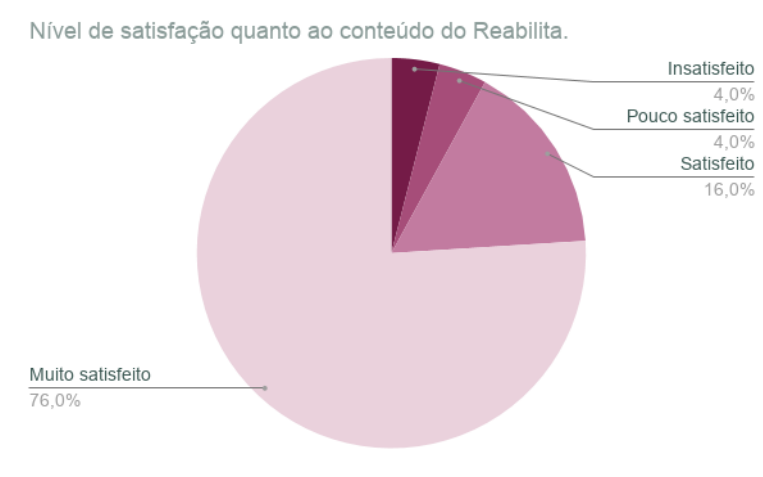

Fonte: Autores (2020)

Dentro da pesquisa, houve 01 respondente que não se adequou à metodologia do curso e não teve suas expectativas atendidas em relação ao conteúdo oferecido pelo curso, como pode ser notado nas baixas porcentagens dos gráficos 9 e 10. É importante ressaltar que nem todos os estudantes terão êxito em metodologias e conteúdo não convencionais, que vem ganhando espaço na educação, mas também é importante que estas respostas não sejam ignoradas e que haja um processo de adaptação e inclusão destes alunos.

\subsection{Experiência com o Reabilita}

A figura 11 apresenta informações sobre a percepção dos ex-alunos em relação ao que foi aprendido no REABILITA. Os termos mais utilizados foram "teórico", "voltado às pesquisas" e "atualizado", seguidos por "prático" e "voltado ao mercado". De fato, a Universidade de Brasília tem caráter teórico/pesquisador, 
visto que é uma escola com grande contribuição acadêmica e investigativa, o que torna o conteúdo oferecido realmente atualizado. Este é o cenário é ideal principalmente àqueles que buscam seguir carreira acadêmica.

Figura 11: Gráfico sobre a percepção a respeito do conteúdo oferecido pelo REABILITA.

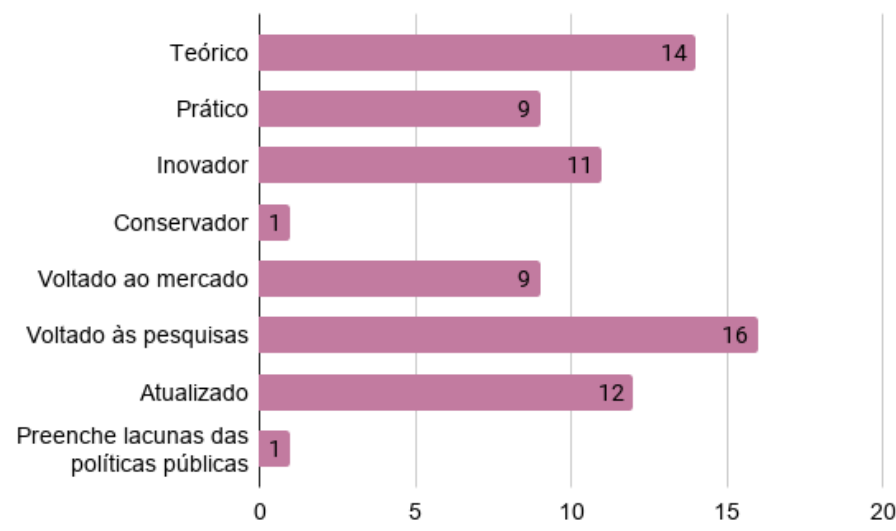

Fonte: Autores (2020)

Apesar da abordagem sobre Sustentabilidade ser de forma mais acadêmica, a avaliação é consistente no âmbito da praticidade e as aplicabilidades dos conceitos estudados ao mercado de trabalho. Podese constatar tal fato a partir da avaliação de aplicabilidade em diversos setores de projetos arquitetônicos e urbanísticos, descrita na tabela 4, onde houve resultados favoráveis à utilização dos conhecimentos nas práticas dos profissionais. Portanto, tais dados comprovam que, apesar do viés teórico, o conhecimento acerca da sustentabilidade oferecido pelo REABILITA consegue ultrapassar a academia e ser empregado de forma técnica e funcional.

Tabela 4: Aplicabilidade dos conceitos de Sustentabilidade em Projetos de Arquitetura e Urbanismo.

\begin{tabular}{lll}
\hline Tipo de projeto & Não Aplicável & Aplicável \\
\hline Projeto Residencial Unifamiliar & $4 \%$ & $96 \%$ \\
Projeto Residencial Multifamiliar & $4 \%$ & $96 \%$ \\
Projeto Residencial Multifamiliar de Alta Densidade & $8 \%$ & $92 \%$
\end{tabular}


Projeto Comercial de Pequeno Porte (ex.: lojas, escritórios, etc.)

\begin{tabular}{ll}
$12 \%$ & $88 \%$ \\
$16 \%$ & $84 \%$ \\
$12 \%$ & $88 \%$ \\
$12 \%$ & $88 \%$ \\
$28 \%$ & $72 \%$ \\
$4 \%$ & $96 \%$ \\
& \\
\hline $8 \%$ & $92 \%$ \\
& \\
$16 \%$ & $84 \%$ \\
$4 \%$ & $96 \%$ \\
\hline
\end{tabular}

Projeto Comercial de Médio Porte (ex.: galerias ou centros comerciais)

Projeto Comercial de Grande Porte (ex.: Shoppings,

Aeroportos, etc.)

Projetos Governamentais

Projetos Hospitalares

Projetos Urbanos de Pequeno Porte (ex.: parques, praças, revitalizações, etc.)

Projetos Urbanos de Médio Porte (ex.: Criação de bairros, condomínios, etc.)

Projetos Urbanos de Grande Porte (ex.: Criação de cidades inteiras, grandes mudanças no traçado urbano, desenvolvimento de grandes vias para mudança de fluxo, etc.)

Consultoria Técnica / Ambiental / em Sustentabilidade

Fonte: Autores (2020)

\subsection{Impacto na vida dos profissionais pós Reabilita}

$\mathrm{Na}$ reta final, analisaram-se quais mudanças ocorreram na vida dos profissionais que buscaram aprofundar seus conhecimentos em relação à Sustentabilidade. Para isso, questionou-se aos ex-alunos qual o nível do impacto que a conclusão do curso REABILITA gerou na atuação dos profissionais e, caso tenha ocorrido, qual a qualidade do mesmo. Desta forma, conforme os gráficos das figuras 12 e 13, observou-se que a grande maioria dos ex-alunos sentiu que houve mudança na prática profissional e a avaliaram como sendo ótima ou boa. Apenas 1 respondente não identificou mudanças.

Figura 12: Gráfico sobre a identificação do impacto causado pelo estudo da Sustentabilidade no REABILITA
Figura 13: Gráfico sobre a avaliação do impacto causado pelo estudo da Sustentabilidade no REABILITA

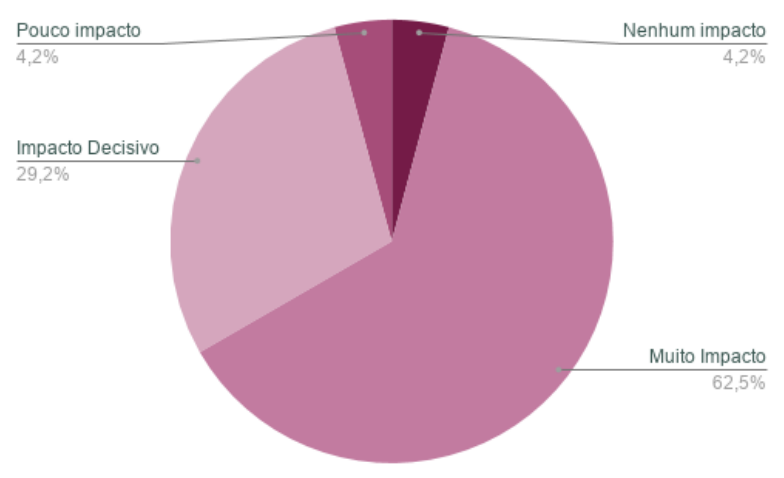

Fonte: Autores (2020)

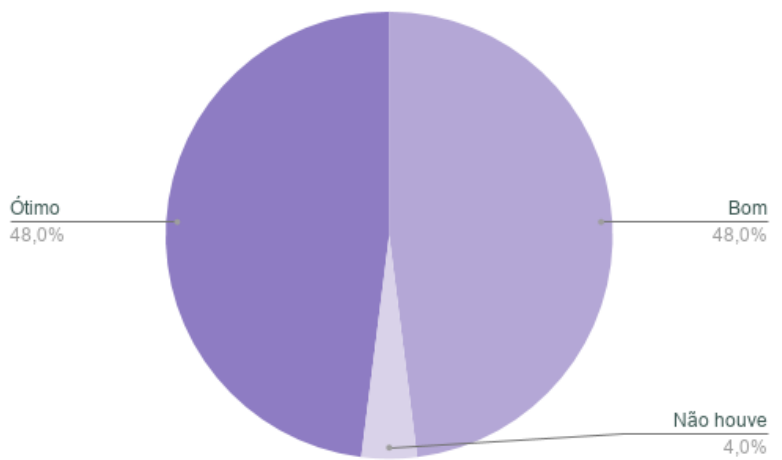

Fonte: Autores (2020)

Além da identificação e avaliação do impacto, os respondentes ainda informaram qual a mudança ocorrida na atuação profissional. A principal e mais citada, foi a facilitação da atuação profissional, no sentido de ter conhecimento técnico suficiente para desenvolver projetos sustentáveis com propriedade, sendo eficientes e eficazes. Em seguida, na ordem de mais citados, vem a ascensão acadêmica continuação da carreira na pós-graduação stricto sensu e/ou como professor; ascensão na carreira 
profissional - como aumento da demanda de trabalho ou promoção; e aumento salarial. Outras mudanças também foram citadas, conforme o gráfico da figura 14.

Figura 14: Gráfico sobre a percepção a respeito do conteúdo oferecido pelo REABILITA.

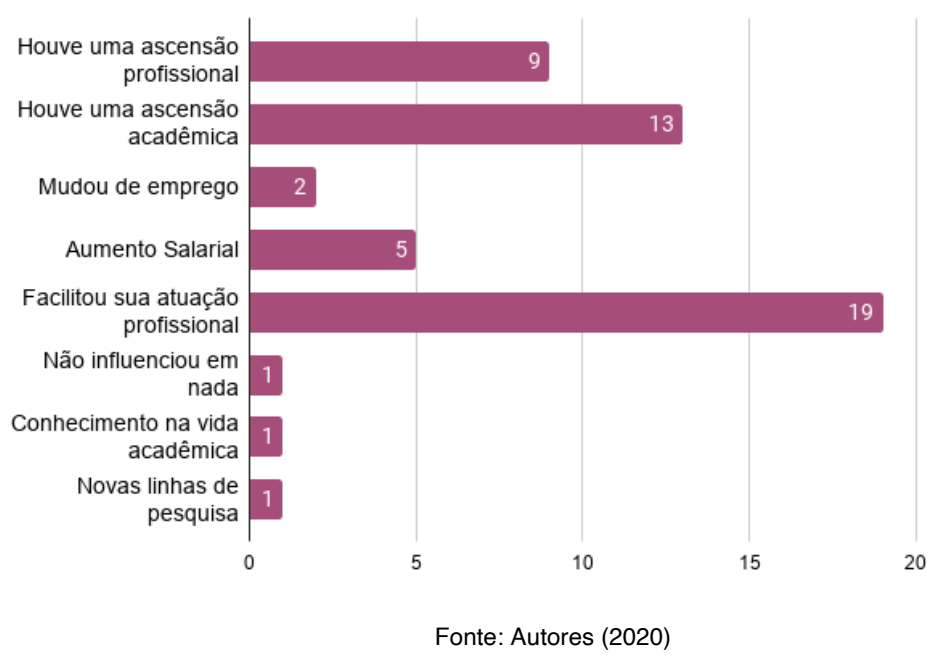

\section{Conclusão}

O ensino da Arquitetura Sustentável no Brasil vem sofrendo mudanças e melhorias, mas ainda é precário. Os currículos acadêmicos das graduações de Arquitetura e Urbanismo ainda tratam a sustentabilidade desassociada das demais disciplinas de projeto, sem o enfoque necessário. Os profissionais sentem a defasagem do ensino no decorrer da atuação profissional. O Reabilita surgiu a partir desta problemática.

A pesquisa desenvolvida e apresentada neste artigo confirma este cenário através de dados obtidos por meio de questionário aplicado aos ex-alunos das edições do Reabilita 1 a 8 . É importante ressaltar que amostra coletada foi de 30 respostas válidas, e que esta quantidade obtida, diante dos quase 600 alunos já matriculados, não invalida a pesquisa realizada. Obviamente a análise apresentada não retrata o curso como um todo, mas ainda assim é possível identificar padrões de como este grupo de profissionais enxergou a experiência da qualificação no âmbito da Arquitetura e Urbanismo Sustentáveis e quais foram as mudanças geradas em suas práticas profissionais.

Vale também ressaltar que as experiências das turmas são variáveis de acordo com a edição do REABILITA, pois este sofre contínuas adaptações e melhorias do conteúdo oferecido aos alunos. Desta forma, o intuito deste trabalho foi ter um panorama do grupo de respondentes, e identificar as turmas refinaria muito os resultados, indo na contramão do objetivo proposto. Uma pesquisa mais profunda a respeito de cada turma, seu conteúdo e como tem sido a atuação dos profissionais pode ser objeto de trabalho posterior, identificando a evolução do estudo em sustentabilidade dentro do REABILITA, os erros e acertos e basear uma adaptação do conteúdo de outras escolas.

De acordo com os dados levantados, concluiu-se que o Reabilita é um curso buscado por pessoas com formação em diferentes cursos de graduação, majoritariamente vindos da Arquitetura e Urbanismo, mas também cursos correlacionados. O grupo é balanceado em relação aos que fizeram o curso de graduação em universidades públicas e particulares, sendo $47 \%$ e $53 \%$, respectivamente. Observa-se que, enquanto aproximadamente $65 \%$ dos alunos graduados em IES públicas consideram a abordagem da sustentabilidade na graduação como sendo boa ou ótima, a maior insatisfação vem da parcela de exalunos que se graduaram em IES privadas, sendo que $56,3 \%$ deste grupo de respondentes consideram 
que o tema foi tratado de forma péssima, ruim ou não houve abordagem, sendo agravada por alunos graduados há mais de 10 anos.

Esta informação leva a concluir que, o contato não aprofundado com a temática aliado às demandas de mercado e relevância do tema, aumentou a busca por cursos de especialização para complementar a defasagem na educação. Outro fator relevante é que, mesmo os ex-alunos que são satisfeitos com a abordagem da sustentabilidade na graduação, buscaram complementar o conhecimento. Estes profissionais indicaram que a credibilidade da Universidade de Brasília e seu corpo docente junto às conveniências oferecidas do método EaD e o estudo técnico da Arquitetura Sustentável foram questões determinantes na escolha do curso REABILITA.

A pesquisa também aponta, com números expressivos, que há grande satisfação dos ex-alunos com o conteúdo oferecido pelo curso - $84 \%$ consideraram muito útil, bem como adaptação de $93 \%$ dos respondentes ao método $\mathrm{EaD}$. Os respondentes indicaram que houve mudanças significativas em suas vidas profissionais. A mais citada foi a facilitação da atuação profissional, seguida de ascensão acadêmica. Associando as informações do caráter acadêmico e investigativo do REABILITA, à parcela de ex-alunos que atuam como professores e pesquisadores, bem como sua ascensão no meio acadêmico, apontam que os profissionais de todo o Brasil buscam se especializar cada vez mais nesta temática e que, consequentemente, o ensino da Arquitetura e Urbanismo Sustentáveis têm conseguido se disseminar de forma mais qualificada.

Além disso, a metodologia EaD amplia as oportunidades de acesso e democratização o ensino, pois a plataforma de Educação a Distância, leva o conteúdo oferecido no Reabilita a pessoas que viam diversas barreiras na continuidade do estudo, tais como o concílio com o trabalho e geolocalização. Por fim, é notável que o estudo da sustentabilidade muda substancialmente a vida dos profissionais, melhora sua da atuação e a empregabilidade dos conceitos, que gera uma onda de mudanças entorno daqueles que fazem uso das alternativas sustentáveis.

\section{Referências Bibliográficas}

BARRETO, M. M.; SALGADO, M. S. (2001). O ensino de arquitetura e a metodologia prática na produção do conhecimento na FAU/ UFRJ. II Encontro Latino Americano sobre ambiente construído, São Pedro, Brasil, Novembro 2001;

BRASIL. Ministério da Educação. Diretrizes Curriculares Gerais Portaria № 1.770 - MEC, 21 de Dezembro de 1994. Disponível em: http://portal.mec.gov.br/sesu/arquivos/pdf/ar_geral.pdf Acesso em 12 de junho de 2020.

BRASIL. Ministério da Educação. O que é educação a distância? 2016. Disponível em: http://portal.mec.gov.br/escola-de-gestores-da-educacao-basica/355-perguntas-frequentes-

911936531/educacao-a-distancia-1651636927/12823-o-que-e-educacao-a-distancia. Acesso em: 26 de Junho de 2020.

BRUNDTLAND, Gro Harlem. Our common future: The World Commission on Environment and Development. Oxford: Oxford University, 1987;

CAVALCANTI, C. C.; STROZZI, G. Os Universitários Brasileiros de EaD frente à Realidade Tríade: Inclusão Digital, Cidadania e Democratização. Revista Brasileira de Aprendizagem Aberta e a Distância, v.7, 2008. Disponível em: https://doi.org/10.17143/rbaad.v7i0.213

CORBELLA, O. D.; YANNAS, S. Em busca de uma arquitetura sustentável para os trópicos: conforto ambiental. Rio de Janeiro: Revan, 2003; 
CORDEIRO, Caio Nogueira Hosannah. A Reforma Lucio Costa e o Ensino da Arquitetura e do Urbanismo da ENBA À FNA (1931-1946). IX Seminário Nacional de Estudos e Pesquisas "História, Sociedade e Educação no Brasil" Universidade Federal da Paraíba - João Pessoa - 31/07 a 03/08/2012 - Anais Eletrônicos - ISBN 978-85-7745-551-5

DOURADO, Brenda M. Sobre o ensino da sustentabilidade ambiental nos cursos de Arquitetura e Urbanismo: avaliação e subsídios. Dissertação de Mestrado em Arquitetura e Urbanismo, Universidade de Brasília, DF, 233p. Brasília, 2015;

FIUZA, P. J. Adesão e permanência discente na educação à distância: Investigação de motivos e análise de preditores sociodemográficos, motivacionais e de personalidade para o desempenho na modalidade. Março de 2012. $145 \mathrm{f}$. Tese (Doutorado em Psicologia) - Instituto de Psicologia, Universidade Federal do Rio Grande do Sul, Rio Grande do Sul. 2012

FRANCO, Maria de Assunção Ribeiro. Planejamento ambiental para a cidade sustentável. $2^{\mathrm{a}}$ edição, São Paulo, Annablume, Fapesp, 2008;

IPEA, INSTITUTO DE PESQUISA ECONÔMICA APLICADA. História - Rio-92. 2009, Ano 7, Edição 56 - 10/12/2009 - $\quad$ Disponível em: https://www.ipea.gov.br/desafios/index.php?option=com_content\&view=article\&id=2303:catid=28\&ltemi $d=23$. Acesso em 22 de maio 2020.

LaSUS. Laboratório de Sustentabilidade Aplicada à Arquitetura e ao Urbanismo. Metodologia do Curso REABILITA. Faculdade de Arquitetura e Urbanismo - Faculdade de Arquitetura e Urbanismo. Universidade de Brasília. Disponível em: https://www.lasusunb.com/metodologia-do-curso.html Acesso em 25/06/2020

LaSUS. Laboratório de Sustentabilidade Aplicada à Arquitetura e ao Urbanismo. Vamos reabilitar nossos lugares? Livreto informativo do REABILITA 10. Faculdade de Arquitetura e Urbanismo. Universidade de Brasília. 2020.

LIMA, K. R. de S. (2007). Educação a distância ou à distância da educação? Universidade e Sociedade, $\mathrm{XVI}(39), 81-91$.

MALHEIROS, Tadeu Fabrício. Pérez, Mario Alejandro. Sampaio, Carlos Alberto Cioce. Zuñiga, Christian Henríquez. Os desafios do tema sustentabilidade no ensino da pós-graduação. RBPG, Brasília, v. 10, n. 21, p. 537 - 552, Outubro de 2013.

ONU, ORGANIZAÇÃO DAS NAÇÕES UNIDAS. Relatório da Conferência da Organização das Nações Unidas sobre Meio Ambiente Humano. Estocolmo, 5-16 de Junho de 1972.

ROMERO, Marta Adriana Bustos. Arquitetura Bioclimática do Espaço Público. UnB, Brasília, 2001.

ROMÉRO, Marcelo de Andrade. Retrofit e APO - Conforto Ambiental e Conservação de Energia / Eficiência Energética. Material Didático do curso de pós-graduação REABILITA, FAU-UnB, 2007.

SOUSA, Maria de Fátima Guerra de. Aprender a Aprender na Educação a Distância. Material Didático do curso de pós-graduação REABILITA, FAU-UnB, 2006.

VILLELA, Dianna Santiago. A sustentabilidade na formação atual do arquiteto e urbanista / Dianna Santiago Villela. Orientador: Roberto Luís de Melo Monte - Mór. Dissertação (mestrado) - Universidade Federal de Minas Gerais, Escola de Arquitetura, 2007. 


\section{Paula Adjuto Martins Graff}

Designer, com ênfase em Produtos, graduada pela Pontifícia Universidade Católica de Goiás (2009), Arquiteta e Urbanista pela Universidade Paulista (2016). Durante o período de graduação em Arquitetura e Urbanismo, estagiou na Sessão de Projetos da Polícia Militar de Goiás, e no Tribunal de Justiça de Goiás. Posteriormente, se tornou Especialista em Reabilitação Ambiental Sustentável Arquitetônica e Urbanística pela Universidade de Brasília - UnB (PPG FAU UnB - 2020). Atua como Arquiteta e Urbanista no desenvolvimento de projetos arquitetônicos Comerciais, Residenciais e de Interiores.

Contribuição de coautoria: fundamentação teórico-conceitual e problematização; pesquisa de dados e análise estatística; elaboração de figuras e tabelas; elaboração e redação do texto; seleção das referências bibliográficas.

\section{Thiago Montenegro Góes}

Arquiteto e Urbanista pela Universidade Federal de Santa Catarina (2011) e mestrado em Arquitetura e Urbanismo pela Universidade de Brasília (2018). Atualmente é doutorando em Arquitetura e Urbanismo pela Universidade de Brasília. Possui uma especialização em Arquitetura, Construção e Gestão da Edificação Sustentável pela AVM Faculdades Integradas (2016) e em Reabilitação Ambiental Sustentável Arquitetônica e Urbanística pela Universidade de Brasília (2017). Realiza em pesquisas de sustentabilidade da edificação, eficiência energética, conforto ambiental e ferramentas computacionais. Possui experiência docente na graduação nos cursos de Arquitetura e Urbanismo no UniProjeção (20182019) e Universidade de Brasília (2019-2020), na pós-graduação no curso de Reabilitação Ambiental Sustentável Arquitetônica e Urbanística pela Universidade de Brasília (2019-2020), assim como cursos de simulação computacional do ambiente construído. Também possui experiência profissional em consultorias e coordenação de projetos, como no projeto LabZero da parceria da UnB e do Procel.

Contribuição de coautoria: fundamentação teórico-conceitual e problematização; revisão do texto.

Como citar: GRAFF, Paula Adjuto Martins, GÓES, Thiago Montenegro. Análise da demanda do estudo em sustentabilidade e o impacto na vida de profissionais pós REABILITA. Revista Paranoá. n.30. Edição Temática: Olhares da Reabilitação Sustentável 3, 2021. DOI 10.18830/issn.1679-0944.n30.2021.18

Editores responsáveis: Caio Frederico e Silva e Daniel Richard Sant’anna 